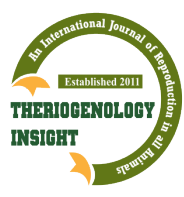

\title{
Management of Dystocia due to Primary Uterine Inertia in Bitch: A Case Report
}

\author{
Gyan Singh ${ }^{1}$, Rajesh Kumar ${ }^{2 *}$, Amit Kumar ${ }^{2}$ and Mukesh Kumari ${ }^{3}$ \\ ${ }^{1}$ Department of Veterinary Clinical Complex, College of Veterinary Sciences, Lala Lajpat Rai University of \\ Veterinary and Animal Sciences, Hisar, Haryana India \\ ${ }^{2}$ Department of Veterinary Gynaecology and Obstetrics, College of Veterinary Sciences, Lala Lajpat Rai \\ University of Veterinary and Animal Sciences, Hisar, Haryana India \\ ${ }^{3}$ Department of Veterinary Medicine, College of Veterinary Sciences, Lala Lajpat Rai University of Veterinary \\ and Animal Sciences, Hisar, Haryana India \\ *Corresponding author: rajeshgangwa1985@gmail.com
}

\begin{abstract}
A five years old bitch was presented to the TVCC, LUVAS, Hisar with the history of commencement of whelping by delivering a dead foetus yesterday, but after that, no other foetuses or placentae were delivered. Primary uterine inertia was confirmed as a cause of dystocia which was immediately intervened by cesarean section and four dead putrefied foetuses were delivered. The bitch recovered without any postoperative complications.
\end{abstract}

Keywords: Cesarean, Dystocia, Putrefied Foetus, Primary uterine inertia

Dystocia is the failure of the dam to expel the foetus at parturition through the birth canal without manual aid. It may be maternal $24.7 \%$ or foetal $75.3 \%$ (Darvelid and Forseberg, 1994) with an overall incidence rate of $5 \%$ (Jackson, 1995). Primary uterine inertia is the most common cause of dystocia in bitches, followed by unusual fetal presentation and posture (Jutkowitz, 2005; Linde- Forsberg, 2005; Smith-Carr, 2005; Kutzler, 2009). The first stage of whelping is characterized by inapparent uterine contractions and progressive dilation of the cervix. The duration is usually $6-12 \mathrm{~h}$ in the bitch, and slightly shorter in the queen (Laliberte, 1986; Johnston, 1986). In some bitches, the first stage of labor can pass without overt clinical signs. The second stage of labor comprises the process of fetal expulsion through a fully dilated cervix. The first puppy is usually born within $4 \mathrm{~h}$ of the onset of stage two labor, and subsequent births occur every $15 \mathrm{~min}$ to $2 \mathrm{~h}$ (Johnston, 1986). This article describes dystocia due to primary uterine inertia and its correction inertia through caesarian section.

\section{CASE HISTORY AND OBSERVATIONS}

A five years old bitch was presented to the TVCC, LUVAS, Hisar with the history of initiation of whelping by delivering a dead foetus yesterday, but after that, no other foetuses or placentae were delivered. Clinical examination revealed rectal temperature $\left(101.5^{\circ} \mathrm{F}\right)$, udder enlargement, swollen vulvar lips also the bitch was dull and depressed with no overt signs of straining. On per-vaginal examination, the

How to cite this article: Singh, G., Kumar, R., Kumar, A. and Kumari, M (2020). Management of Dystocia due to Primary Uterine Inertia in Bitch A Case Report. Theriogenology Insight, 10(1): 23-26.

Source of Support: None; Conflict of Interest: None 
cervix was fully dilated and no foetus could be palpated. Based on patient history, per-vaginal and clinical examination of the case, primary uterine inertia was confirmed as a cause of dystocia which was immediately intervened by cesarean section and four dead putrefied foetuses were delivered.

\section{TREATMENT AND DISCUSSION}

In the present case, manual vaginal delivery could not be performed due to primary uterine inertia. For immediate relief, the cesarean section was planned to perform. The bitch was placed in dorsal recumbency, midventral area was shaved and prepared aseptically (Fig. 1).

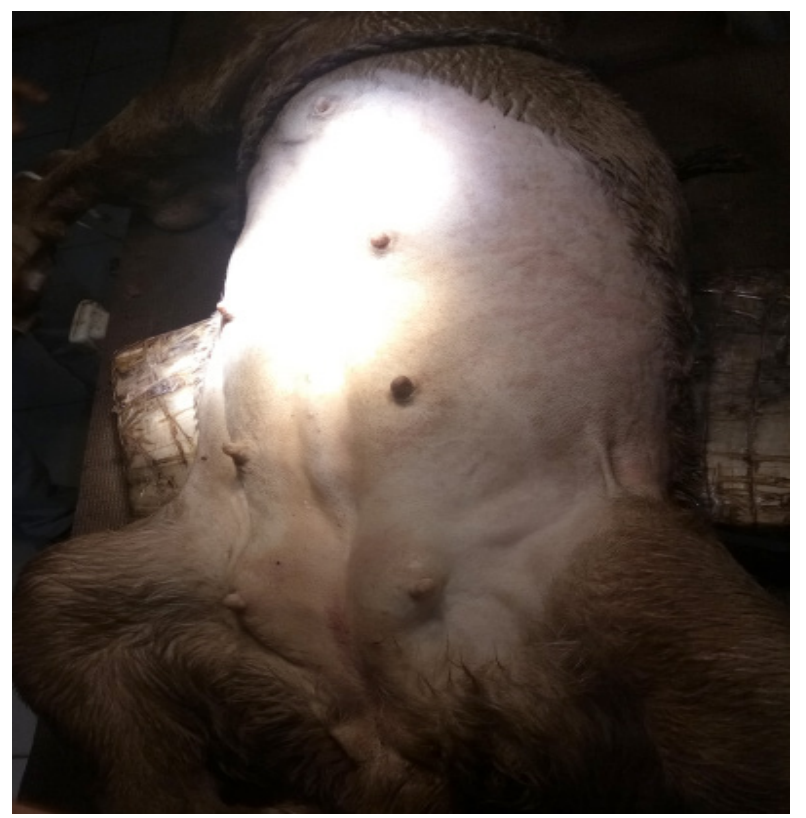

Fig. 1: Midventral area was shaved and prepared aseptically

Atropine sulphate @ 0.04 mg/ kg was administered intramuscularly as premedicant and general anesthesia was achieved by intravenous administration of mixture of Ketamine and xylazine @ $5.0 \mathrm{mg} / \mathrm{kg}$ and 1.0 $\mathrm{mg} / \mathrm{kg}$ respectively. Laparotomy was performed through a standard mid ventral incision (Fig. 2) and the uterus was exteriorized (Fig. 3) and $8 \mathrm{~cm}$ incision over uterus was made before uterine bifurcation.

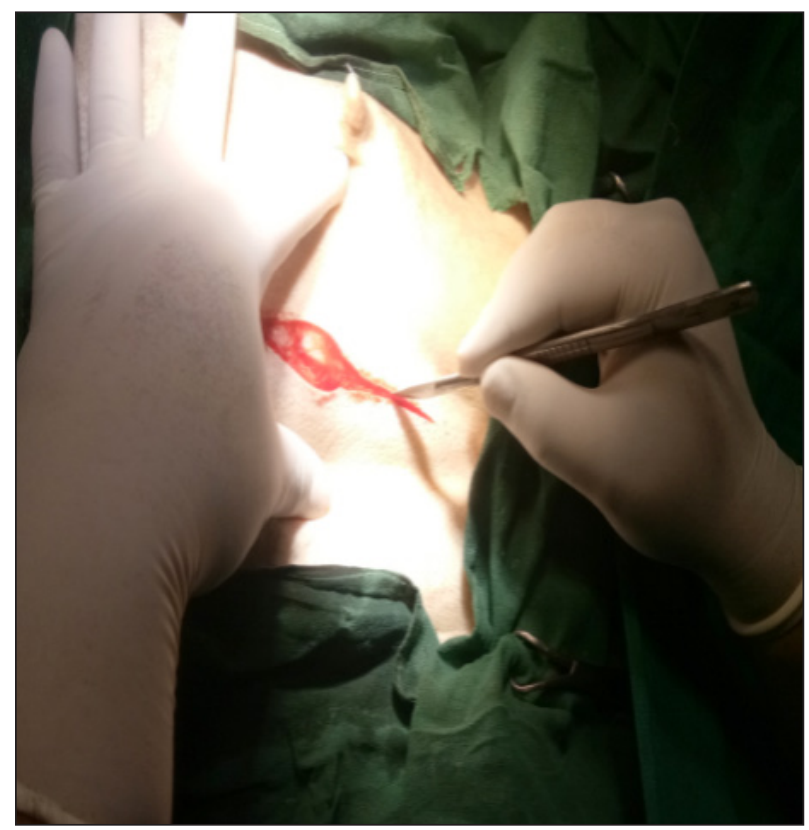

Fig. 2: Mid ventral incision for exteriorization of uterus

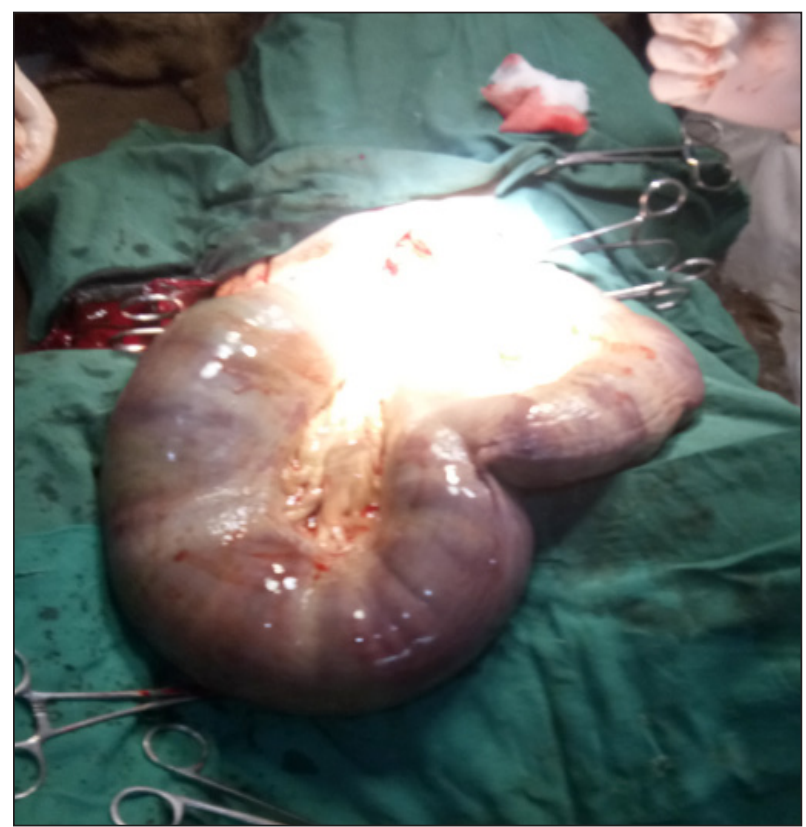

Fig. 3: Exteriorized uterus

Four putrefied dead foetuses (Fig. $4 \& 5$ ) were delivered. The uterus was checked for presence of additional foetuses if any. Then the uterus 
was irrigated with normal saline to evacuate the lochial discharge completely. The uterine incision was closed by double inversion suture pattern using chromic catgut 1 (Ethicon, Johnson \& Johnson).

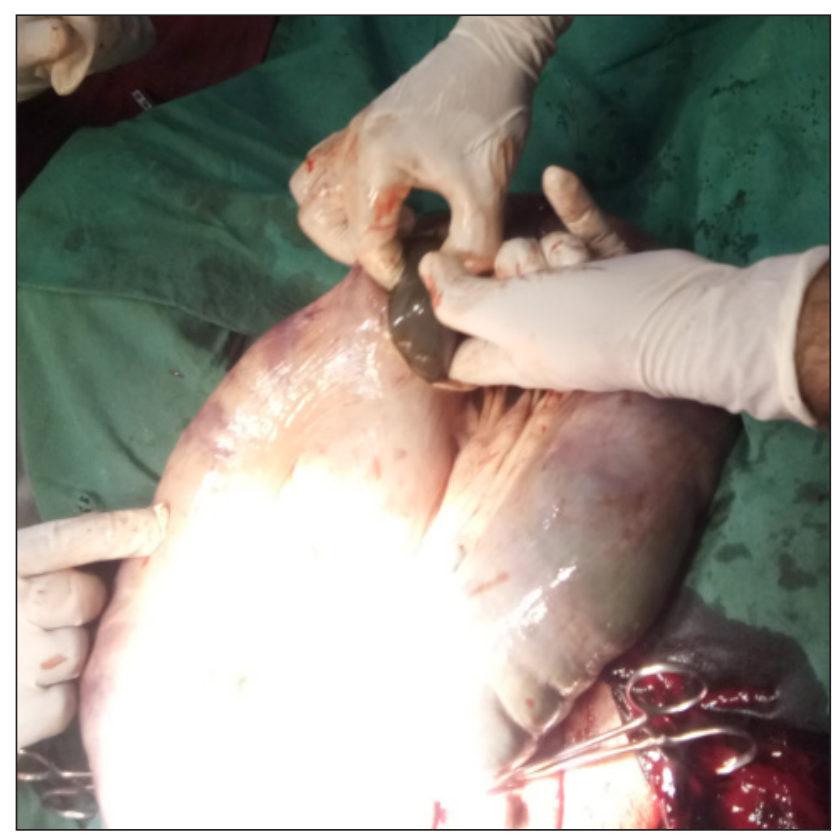

Fig. 4: Removal of putrefied foetuses from incision at body of uterus

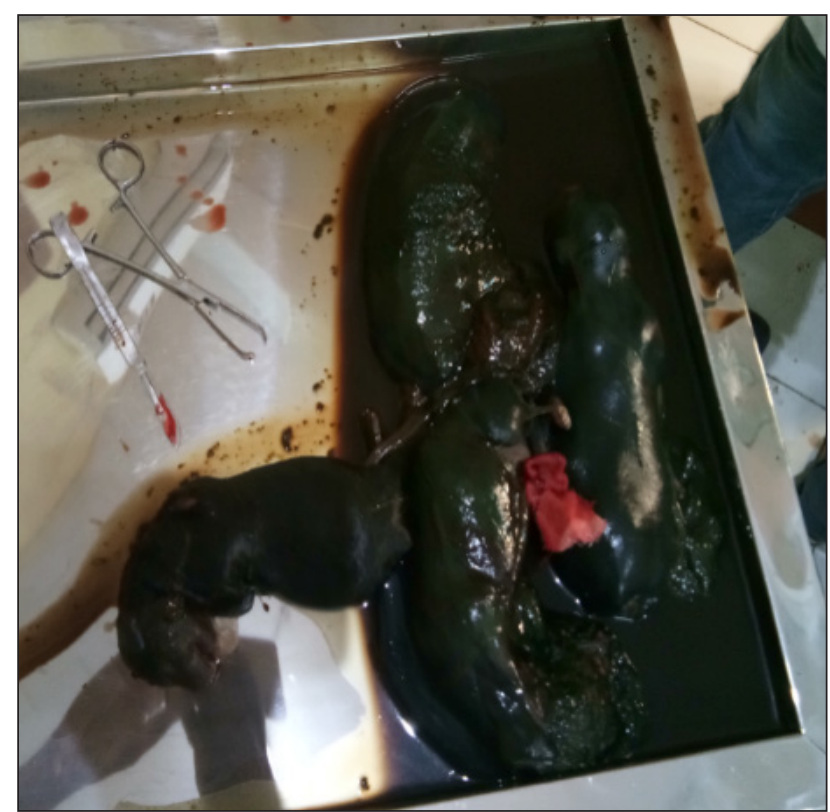

Fig. 5: Putrefied foetuses after removal from uterus
Peritoneum and lineaalba were sutured using lock-stitch suture pattern followed by subcuticular sutures with chromic catgut no. 1 (Ethicon, Johnson \& Johnson). The skin was closed with black braided silk no. 1 in cross mattress pattern and a protective bandage was applied. Postoperatively the animal was administered with DNS $(100 \mathrm{ml}, \mathrm{i} / \mathrm{v})$, Metronidazole (50 ml, i/v), Cefotaxime (50 mg/ $\mathrm{kg}, \mathrm{i} / \mathrm{m})$, Ketoprofen $(1.0 \mathrm{mg} / \mathrm{kg}, \mathrm{i} / \mathrm{m})$, Tribivet $(1.0 \mathrm{ml}, \mathrm{i} / \mathrm{m})$ for five consecutive days with daily dressing and skin sutures were removed on 10th post-operative day.

Dystocia is a common emergency in dogs and can be life-threatening for both mother and fetus. The most common cause of maternal dystocia in bitch is primary uterine inertia (Gaudet, 1985; Darvelid and Linde-Forsberg, 1994). Primary uterine inertia could be either complete or partial. In complete primary uterine inertia, the bitch does not start labor. In partial primary uterine inertia, the bitch starts to deliver her puppies, but the labour ends prematurely, despite the presence of a patent birth canal (Bergstrom et al. 2006). Uterine contractions are present in initial stages of whelping but cease later. In the present case, cervix was fully dilated, with the history of delivery of one dead foetus yesterday and per vaginally no foetus was palpated in the vaginal passage, suggesting that uterine contractions could have stopped and partial primary uterine inertia was setup in the dam which requires immediate intervention for welfare of dam and foetuses. Primary uterine inertia may occur due to deficiency of oxytocin, serum calcium, and blood glucose (Linde-Forsberg and Eneroth, 2000). Thus, blood profile could be the tool to find the relation between serum calcium level and uterine inertia cases. Successful management of dystocia depends upon the correct diagnosis of its causes and adoption of suitable corrective measures. Cesarean section should be the first line of treatment in all cases of complete or partial uterine inertia to maximize the foetal survival rate (Prashant Kumar et al. 2018). 
Therefore, cesarean section was performed in this case for providing immediate relief to the bitch.

\section{REFERENCES}

Bergstrom, A., Fransson, B., Lagerstedt, A.S. and Olsson, K. 2006. Primary uterine inertia in 27 bitches: aetiology and treatment. J. Small Anim. Pract. 47: 456-460.

Darvelid, A.W. and Linde-Forsberg, C. 1994. Dystocia in the bitch: a retrospective study of 182 cases. $J$. Small Anim. Pract. 35: 402-407.

Gaudet, D.A.J. 1985. Retrospective study of 128 cases of canine dystocia. J. American Anim. Hospital Assoc. 21: 813-818.

Jackson, P.G.G. 1995. Handbook of Veterinary Obstetrics, W.B. Saunders Co., Philadelphia, USA.

Johnston, S.D. 1986 Parturition and dystocia in the bitch. In: Morrow DA, editor. Current therapy in theriogenology 2. Saunders; pp. 500-1.

Jutkowitz, L.A. 2005. Reproductive emergencies. Vet. Clin. Small Anim. Pract., 35: 397-420.

Kutzler, M.A. 2009. Dystocia and obstetric crises. In: (eds: Silverstein DC, Hopper K) Small Animal Critical Care Medicine. Elsevier Saunders, St. Louis, pp. 611-615.
Laliberte, L. 1986. Pregnancy, obstetrics, and postpartum management of the queen. In: Morrow DA, editor. Current therapy in theriogenology 2 . Saunders; pp. 812-21.

Linde-Forsberg, C. and Eneroth, A. 2000. Abnormalities in pregnancy, parturition and the periparturient period. Textbook of Veterinary Internal Medicine, Ettinger SJ, Feldman EC, $5^{\text {th }}$ Edn., Saunders, Philadelphia. pp. 1527-1539.

Linde-Forsberg, C. 2005. Abnormalities in pregnancy, parturition, and the periparturient period. In: (eds: Ettinger SJ, Feldman EC) Textbook of Veterinary Internal Medicine, $6^{\text {th }}$ Edn. Elsevier Saunders, St. Louis, pp. 1655-1667.

Kumar, Prashant, Krishnaswamy, A. and Walikar, A. 2018. Evaluation of treatment protocols for complete primary uterine inertia in female dogs. The PharmaInnov. J., 7(6): 661-664.

Smith-Carr, S. 2005. Gynecologic emergencies. In: (eds: Ettinger SJ, Feldman EC) Textbook of Veterinary Internal Medicine, $6^{\text {th }}$ edn. Elsevier Saunders, St. Louis, pp. 450-452. 